\section{Extinction in the presence of free food*}

\author{
SIDNEY ENKEMA, ROBERT SLAVIN, CARL SPAETH \\ and ALLEN NEURINGER \\ Reed College, Portland, Oreg. 97202
}

After pigeons were trained to peck a response disk for food reinforcement, responding was extinguished by withholding the food. During extinction training, freely available food was added to the chamber. Responding was found to extinguish rapidly in the presence of the free food. However, when the free food was removed, many more extinction responses were emitted until approximately the same total number of responses to extinction were emitted as by a control group that never experienced free food. Thus, free food temporarily suppressed responding in extinction; removing the free food caused responding to return to high strength.

The frequency of an operant response increases when it is reinforced and decreases or extinguishes when reinforcement is withheld (Skinner, 1938). Recently, much research has been done concerning concurrent reinforcement of two operant responses (Catania, 1966). However, relatively little is known about the course of extinction of one response when a competing response is reinforced. Leitenberg, Rawson, \& Bath (1970) examined extinction of one leverpress response in rats under conditions in which presses on an alternative lever were reinforced. The rats were initially trained to press the first lever for food reinforcement. While that response was being extinguished, the responses on the alternative lever were reinforced. Leitenberg et al found that, under these conditions, responses to the frrst lever extinguished more rapidly than under a control condition in which the alternative response was never reinforced. However, when reinforcement for the alternative response was discontinued, the animals returned to the first lever and emitted approximately the same total number of extinction responses as was emitted by a control group. Thus, reinforcing an alternative response facilitated extinction of the original response, but the facilitation was temporary.

In the Leitenberg et al study, the alternative response was identical to the first response: they both were presses on response levers. Thus, the number of responses to extirfction on the first lever might háve been influenced by the reinforcers obtained for responding on the alternative lever. Transfer of training, or generalization, effects might have increased the

*This research was supported by Grant MH-19602-01 from the National Institute of Mental Health and by a National Science Foundation Institution grant awarded to Reed College. Reprints can be obtained from Allen Neuringer, Reed College, Portland, Oreg. 97202 strength of responses on the first lever. The present study tests this possibility by extinguishing one response, while a strikingly different alternative response provides reinforcement. While a pigeon's keypeck response-which had been reinforced with grain-was being extinguished, a cup filled with freely available grain was provided.

Animals and humans emit operant responses for food reinforcement while identical food is freely available (Jensen, 1963; Neuringer, 1969, 1970; Singh, 1970). Neuringer (1969) showed that responses extinguish rapidly when not reinforced and free food is available. The present work first tests Neuringer's (1969) results he used, e.g., the pigeon here is $24 \mathrm{~h}$ deprived and is given $1-h$ sessions daily, whereas in the Neuringer study, the pigeon was not deprived and was kept in the experimental chamber $24 \mathrm{~h}$ per day. The second, and major, question then asked was: would the freely available food cause a temporary suppression in extinction responses, a result analogous to that of Leitenberg et al? An affirmative answer to this question would support the generality, and therefore the significance, of the Leitenberg et al finding.

Eight homing pigeons, with varieties of previous experimental experiences, were at approximately $80 \%$ of their free-feeding body weights prior to each experimental session.

$$
\text { APPARATUS }
$$

A $12 \times 12 \times 16$ in. wire-mesh cage served as the experimental chamber. The front wall of the cage was a metal panel containing a $1 / 2$-in.-diam transilluminated response disk which was located $3 \mathrm{in}$. to the right of center and $8 \mathrm{in}$. above the floor. Effective pecks to the disk produced a feedback click from a relay mounted behind the front panel. Below and to the left of the response disk was a 2 -in.-diam hopper access hole, the bottom of with parameters different from those which was 3 in. above the cage floor. Whenever the hopper operated, the hopper opening was illuminated by a 7-W white bulb. During conditioning, the hopper contained mixed grain for reinforcement; during extinction, the grain was removed from the hopper. In the rear right corner of the chamber was secured a plastic coffee cup, 6 in. high and 4 in. in diam. The cup was sometimes filled with grain identical to that presented in the hopper and was sometimes empty, as will be explained below. Diffuse overhead light and masking noise were continuously present during experimental sessions. The experimental chamber was contained within a sound-attenuating, lightproof outer box. Electromechanical control equipment was located in an adjacent room. PROCEDURE

Preliminary Training

All Ss were given 12 sessions of preliminary training on a variable-interval $30-\mathrm{sec}$ (VI $30-\mathrm{sec}$ ) schedule of reinforcement. On the average of once every $30 \mathrm{sec}$, pecks to the lighted response disk produced $3 \mathrm{sec}$ of access to grain in the hopper. Sessions terminated after 31 reinforcements were received.

Experimental Group

After rates of responding had stabilized in the preliminary condition, the eight birds were divided into two matched groups according to response rates. Responding was extinguished in the experimental group by (1) removing grain from the hopper and (2) placing freely available grain in the cup located in the rear of the chamber. Responses to the key continued to activate the hopper on the VI schedule, but the hopper was now empty. Note that this method of extinction is somewhat novel-responses usually have no effect-and was used to minimize the differences between conditioning and extinction conditions.

Sessions were started only after the $S$ began eating from the free-food cup. Preliminary work had indicated that birds would sometimes completely ignore the free food upon first being placed in the experimental chamber. Therefore, care was taken to orient the Ss towards the foodcup, and, in addition, the response key was darkened and inactivated. The session began as soon as the $S$ ate from the free food. In no case did a bird peck the key before eating free food. Sessions were terminated after 31 hopper presentations or after $60 \mathrm{~min}$, whichever occurred first.

Since all four birds ate large amounts of grain from the free-food cup, gaining as much as $60 \mathrm{~g}$ in one session, 3 or 4 days had to pass before the birds would return to their $80 \%$ 


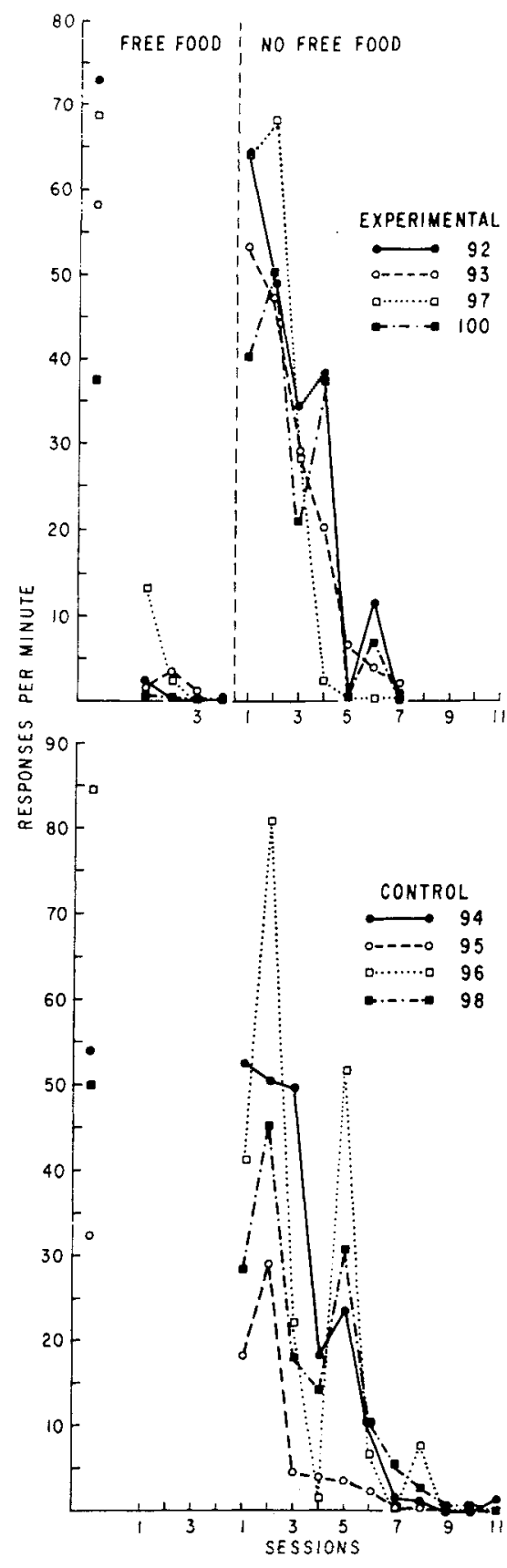

Fig. 1. Rates of responding during extinction for (a) birds that received free access to a cup filled with grain during the first 4 days of extinction (experimental group, top), and (b) birds that never received free food (control group, bottom). The points to the left were obtained during preliminary VI training.

body weights. Thus, 3 or 4 calendar days separated each experimental session in this phase of the experiment. The birds were given four extinction sessions in the presence of free grain. During the next seven sessions, free grain was removed from the cup. Except for the absence of the free grain, the conditions in the chamber were identical to those during the original four extinction sessions. Sessions were given on consecutive days during this phase.

\section{Control Group}

The four control birds received 11 sessions of extinction training. Free grain was never present for these birds. In all other respects, the conditions in the experimental chamber were identical to those for the experimental birds. To keep the amounts of weight gained by experimental and control birds approximately the same, the control birds were given $60 \mathrm{~min}$ of free access to grain in their home cages after each of the first four extinction sessions. Thus, these birds gained approximately the same weight after each of the first four sessions as did the experimental birds, and the numbers of calendar days between each session were identical for the two groups.

\section{RESULTS AND DISCUSSION}

The top of Fig. 1 shows rates of responding for each of the experimental birds. The points to the left show rates of responding during the last session of preliminary training. In the sessions of extinction with free food present, responding decreased precipitously until, during the fourth session, practically no responses were emitted. During these sessions, the birds ate free grain for approximately 10-20 $\mathrm{min}$ and then generally stood quietly for the remainder of the session. Only during the first session was there appreciable responding to the key after the birds ate from the cup of free grain.

When free food was removed from the cup, rates of responding increased dramatically. Response rates on the first day of extinction without free food approximated those during the last day of preliminary VI training. During the next six sessions, rates of responding decreased systematically until, during the final session, practically no responses were emitted.

The bottom of Fig. 1 shows rates of responding for each of the control Ss. Rates of responding decreased until, by the seventh session, practically no responses were emitted.

Figure 2 shows arithmetic averages of the rates of responding for the two groups. After free food was withdrawn from the experimental birds, the two groups' average extinction response curves were practically identical. The total number of responses emitted by the experimental Ss during the 11 days of extinction were $3,994,3,274$, 3,416 , and 3,237 , for an overall average of 3,480 . The average numbers of responses emitted by the control Ss were $4,026,1,485,4,752$, and 2,891 , for an overall average of 3,288 . Thus, there was little difference between the average numbers of responses emitted to extinction by the two groups.

The present results show, first, that presenting free food to pigeons during extinction caused an immediate suppression in responding. This finding is similar to that obtained by Neuringer (1969) and indicates that responding for food in the presence of free food is not simply due to extinction responses. Animals will respond for food in the presence of free food; however, very few extinction responses will be emitted when free food is available.

Second, when the free food was removed, responding in extinction returned to high strength and there was no ultimate savings in the total number of responses emitted before extinction was complete. Analogous findings have been obtained in studies of drive level and punishment. Barry (1958), for example, showed that when drive level is decreased to low strength at the beginning of extinction, there is a temporary decrease in responding; increasing drive to its previously high level causes a return to high-response strength. Similarly, Estes (1944) and Skinner (1938) found that responses were suppressed during extinction when punishment was made contingent upon the response; however, responding returned to high strength when the punishment was discontinued.

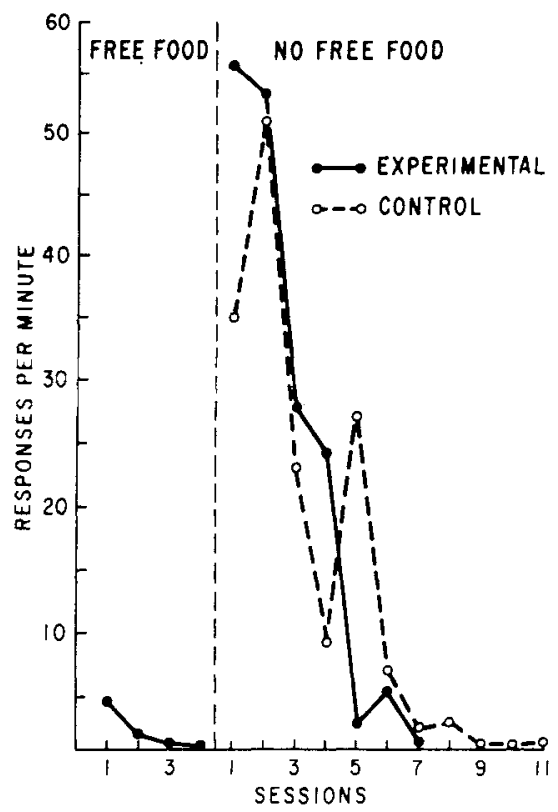

Fig. 2. Averages of the experimental and control groups' rates of responding during each session of extinction. 
The present results suggest that the Leitenberg et al (1971) findings were not caused by the similarity between original and alternative responses. In the Leitenberg et al experiment -where the original and alternative responses were both leverpresses for food-and in the present case-where one response was pecking a disk. for food and the alternative response was eating from a free-food cup-it was found that an alternative source of food during extinction suppressed responding. But when the alternative food source was removed or inactivated, responding in extinction returned to high strength. Thus, extinction responses are suppressed when (1) the responses are punished,
(2) drive level is decreased, (3) a similar competing response is made available, and (4) a dissimilar competing response is made available. The suppression lasts, however, only as long as the given operation is maintained.

\section{REFERENCES}

BARRY, H., III. Effects of strength of drive on learning and on extinction. Joumal of Experimental Psychology, 1958, 55. 473-481.

CATANIA, A. C. Concurrent operants. In W. K. Honig (Ed.), Operant behavior: Areas of research and application. New York: Appleton-Century-Crofts, 1966.

ESTES, W. K. An experimental study of punishment. Psychological Monographs.
1944,57 , Whole No. 263.

JENSEN, G. D. Preference for bar pressing over "free-loading" as a function of number of rewarded presses. Journal of Experimental Psychology, 1963, 65, 451-454.

LEITENBERG, H., RAWSON, R., \& BATH, $K$. Reinforcement of competing behavior during extinction. Science, 1970, 169, 301-303.

NEURINGER, A. J. Animals respond for food in the presence of free food. Science, $1969,166,399-401$.

NEURINGER, A. J. Many responses per food reward with free food present. Science, 1970, 169, 503-504.

SINGH, D. Preference for bar pressing to obtain reward over freeloading in rats and children. Journal of Comparative \& Physiological Psychology, 1970, 73, $320-327$.

SKINNER, B. F. The behavior of organisms. New Yodk: Appleton-Century-Crofts, 